\title{
A DIMENSÃO EDUCATIVA DA LUTA POR SAÚDE NO MOVIMENTO DE MULHERES CAMPONESAS E OS DESAFIOS POLÍTICO-PEDAGÓGICOS PARA A EDUCAÇÃO POPULAR EM SAUUDE
}

\author{
Vanderléia Laodete Pulga Daron
}

\begin{abstract}
RESUMO: Este artigo apresenta algumas reflexões e aprendizados obtidos na investigação sobre a luta por saúde desenvolvida pelo Movimento de Mulheres Camponesas no Rio Grande do Sul, através da análise de observações, registros, documentos, histórias de vida e entrevistas feitas com mulheres que dele participam. Revela as bases que sustentam e fundamentam a emergência da luta por saúde neste Movimento e a dimensão educativa, política e terapeutica que nele se expressa. Apresenta os desafios políticopedagógicos que emergem desta experiência para a educação popular em saúde.
\end{abstract}

Palavras-chave: Mulheres camponesas. Saúde. Educação popular em saúde. Gênero.

THE EDUCATIVE DIMENSION OF THE SOCIAL FIGHT FOR HEALTH IN the Movement of Peasant Women and the political-Pedagogical CHALLENGES FOR A POPULAR EDUCATION IN HEALTH

ABSTRACT: This paper presents some reflections and apprenticeships based on an investigation of the Movement of Peasant Women's fight for health, through the analysis of observations, reports, documents, life stories and interviews made with women who participate in this organization. It unveils the bases that support and found the emergency of the fight for health in this organization and the educative, political and therapeutic dimension

Mestre em Educação e educadora popular. Atua no Grupo Hospitalar Conceição (RS). E-mail: vanderleia.daron@gmail.com 
expressed in it. It presents the political-pedagogic challenges for the popular education in health, which emerge from this experience.

Key words: Peasant women. Health. Health popular education. Gender.

\section{Introdução}

$\mathcal{E}$

sta reflexão é parte das muitas descobertas obtidas na pesquisa realizada junto ao Movimento de Mulheres Camponesas (MMC) do Rio Grande do Sul (RS), em 2003, na época MMTR. ${ }^{1}$ A pesquisa procurou analisar porque a luta por saúde se constituiu como uma das lutas centrais neste movimento. Para isso, foi desenvolvida uma pesquisa focal na região litorânea do RS, articulada com as instâncias organizativas em nível estadual e nacional do MMC, por meio da realização de entrevistas com mulheres camponesas dos grupos de base, de dirigentes locais, da direção estadual e nacional; reflexôes a partir de vivências em encontros, oficinas, observações, análise de relatos e histórias de vida de mulheres camponesas vinculadas ao movimento, registradas no diário de campo. Além disso, houve a análise e a sistematização de documentos deste Movimento, em seus vários níveis organizativos, para a compreensão histórica da sua atuação social popular. É uma pesquisa complexa, que buscou a articulação do enfoque qualitativo da pesquisa em saúde (Minayo, 1996), com abordagem histórica e dialética (Marx e Gramsci), tendo como referência a forma de pesquisa com as classes populares (Marcon, 1999; Paludo, 2001), na perspectiva de gênero (Muraro, 1983; Gebara, 2000). Assim, a reflexão aqui proposta constitui-se em uma parte das muitas construções e análises oriundas desta pesquisa, que se encontra na íntegra na dissertação de Mestrado.

Primeiramente, vale destacar que o MMC do Rio Grande do Sul é uma organização da sociedade civil, sem fins lucrativos, formada por mulheres trabalhadoras rurais. Caracteriza-se como um movimento social popular, de caráter autônomo, democrático, feminista e de massas. Luta pela mudança nas relações de opressão e discriminação entre homens e mulheres e pela transformação da sociedade capitalista, visando à construção de uma nova sociedade, que resgate o valor humano, 
as relações entre as pessoas e com a natureza, numa perspectiva socialista e democrática. Este movimento foi se organizando e se constituindo a partir de sua inserção no processo mais amplo da luta popular (de classe) e feminista (de gênero) no Brasil, onde as mulheres sempre estiveram presentes na construção da história da humanidade e nas lutas por justiça, desde os tempos mais remotos até nossos dias. Apesar de poucos registros, as mulheres têm uma efetiva participação na construção histórica do Brasil. São histórias vividas com festa e com sangue, mas que pouco foram contadas ou escritas. As mulheres estão gerando riquezas, produzindo alimentos, embalando vidas, organizando lutas por libertação. Assim, as mulheres camponesas constroem lutas e resistem à opressão, enfrentando os mais diversos mecanismos de discriminação. O MMC é formado e dirigido pelas mulheres camponesas. Enraizado nas comunidades rurais através dos grupos de mulheres, desenvolve processos formativos e lutas por direitos, implanta experiências inovadoras e enfrenta o capitalismo e a cultura histórica patriarcal, instituída no Brasil rural desde o período da colonização, e busca a superação de todas as formas de opressão, exploração, discriminação e violência.

As principais questôes que historicamente vêm mobilizando as mulheres camponesas do Brasil dizem respeito à luta por direitos, valorização das mulheres, em defesa da vida e de uma sociedade justa, com novas relaçôes entre os seres humanos e destes com a biodiversidade. A luta pelo reconhecimento da profissão de trabalhadora rural e, com isso, dos direitos previdenciários demarcou a construção do Movimento. Aliado a isso, a luta pelo direito à saúde é um marco fundamental do processo de luta, resistência e dinamismo do trabalho de base das mulheres camponesas.

O caminho percorrido nesta pesquisa possibilitou perceber que as bases que dão solidez à luta por saúde no Movimento estão diretamente vinculadas à realidade concreta vivenciada pelas mulheres camponesas, para as quais as condições de vida e saúde são negadas em nome dos interesses mercantis dominados por grupos hegemônicos internacionais e que têm incidência direta no cotidiano de vida de milhares delas, que ficam doentes e sem acesso aos direitos, tanto de atenção à saúde quanto de melhores condições de vida no campo. Essa realidade é a matriz emergente da luta por saúde e dignidade no MMC 
A dimensão educativa da luta por saúde no Movimento de Mulheres Camponesas...

e possibilita compreender o paradoxo entre o aumento das necessidades de atenção à saúde do povo e os interesses mercantis que buscam mais lucros.

Evidencia-se, por outro lado, o quanto a luta e o trabalho realizado pelas mulheres vêm contribuindo para o desvelamento dos problemas e, ao mesmo tempo, buscando soluções coletivas, apontando saídas e conquistando melhorias nas condiçōes de vida e de direitos, dando passos em relação à libertação das mulheres e à mudança de relaçôes sociais de gênero. A experiência de resistência vivenciada pelas mulheres camponesas organizadas e a complexidade das questóes que dela emergem são muito maiores do que a capacidade de traduzi-las numa investigação, que sempre tem seus limites e seus recortes de análise. A pesquisa e o Movimento, contudo, são reveladores de um conjunto de questôes que nos fazem repensar os modos de vida, as relações de produção e de reprodução da vida, do trabalho, do poder e do saber e seus condicionantes no campo da saúde. Como experiências de resistência, revelam que os sujeitos das classes populares, com seus saberes, sua cultura, suas condições materiais, humanas e políticas, conseguem construir formas de organizar a vida e a saúde.

A dimensão educativa da luta por saúde no MMC

O trabalho realizado pelas mulheres camponesas se dá de forma processual e articula a formação, a organização, as lutas e a construção das experiências de promoção à saúde, que se constituem em formas de resistência popular no campo. Este processo produz a conscientização das mulheres, a sua construção como sujeito ativo, em que as mulheres transformam a vida e as relações, permeadas por uma mística libertadora e feminista, imbricadas no eixo gênero, classe e projeto popular.

Esta práxis é portadora de uma dinâmica educativa que revela a capacidade das mulheres camponesas de articulação entre a prática cotidiana com a reflexão teórica, potencializando a transformação da realidade e das relaçóes humanas, sociais e culturais. Fundamenta-se na dimensão integral do ser humano, suas relações histórico-culturais com o mundo e com a biodiversidade. A busca pela liberdade concreta, universal e conquistada pela luta política, que ocorre de forma histórica e processual, se faz presente na vida de cada mulher militante. Tem 
como base norteadora a metodologia de construção de processos político-organizativos, formativos e de resistência popular, próprios da concepção e das práticas da educação popular. Tem como sujeitos centrais as mulheres camponesas que participam do MMC, reconhecendo-as como pessoas, cada qual como um ser integral que constrói conhecimento com o outro, numa relação de alteridade mediatizada pelo mundo.

A base da relação entre os sujeitos do processo é a realidade concreta, o projeto popular que querem construir, mediado pelo projeto político e pelas estratégias deste Movimento. Busca a transformação da realidade concreta, tanto cotidiana quanto da estrutura da sociedade, bem como a transformação humana, das relações sociais, de gênero, raça e classe, das relações políticas com base na democracia participativa. A par da transformação está a base de libertação de todas as formas de opressão, exploração, discriminação, violência e a construção de uma nova sociedade e da cidadania e emancipação da mulher e das classes populares.

Nesse sentido, os valores éticos, a coerência, o coletivo e a postura aberta, de busca de ser mais, de companheirismo e solidariedade, são alguns determinantes que permeiam o trabalho destas mulheres. Assim, com base assentada em princípios e valores, comprometidas com a mística do projeto popular - libertador e emancipatório das mulheres e das classes populares que dão sustentação -, as mulheres enfrentam a realidade de forma organizada para transformá-la e demonstram como sua práxis é portadora de uma dinâmica educativa que se expressa de diversos modos e que produz, pela sua ação, novos saberes e novas práticas.

\section{O modo de cuidar como processo educativo-terapêtico}

As mulheres camponesas têm um jeito próprio de cuidar da vida e da saúde que se expressa nas práticas populares de cuidado que desenvolvem, articuladas com a luta para a garantia de um sistema público e universal de saúde e com um novo modo de viver no campo. Este modo singular de cuidado e de promoção da vida, saúde e cidadania, pode-se identificá-lo como um processo educativo-terapêutico. Parte-se do pressuposto de que esse tipo de trabalho só pode ser realizado se for em grupo, com organização de base, trabalho coletivo e comunitário e o fazer com o que se tem, se sabe e se pode, sem depender de outros. 
A dimensão educativa da luta por saúde no Movimento de Mulheres Camponesas...

Entre os vários elementos elencados pelas mulheres camponesas, a acolhida e a capacidade de escuta e de respeito a cada pessoa que participa do grupo, ou com quem busca alguma forma de cuidado, marcam profundamente este trabalho.

O diálogo é a base da relação, na qual tanto quem cuida como quem é cuidado são sujeitos. O estabelecimento do diálogo possibilita a problematização da relação entre os sintomas aparentes de dor e sofrimento com as possíveis causas. Muitas vezes, as pessoas saem já sem dor porque precisam ser acolhidas e valorizadas; outras necessitam de um diagnóstico mais preciso e são encaminhadas ao sus; outras, ainda, são cuidadas e acompanhadas.

O processo da saúde como busca de equilíbrio e energia e de construção de um modo de vida saudável perpassa o conjunto das ações desenvolvidas. Percebe-se que as mulheres têm e, ao mesmo tempo, buscam permanentemente compreender a dinâmica da vida em sua teia de complexidades e relaçóes. Ao mesmo tempo, no tratar cada pessoa como ser único, há uma relação de amor e afeto e a conjugação de várias ações, orientações de conduta, postura e mudança de comportamento e estilos de vida, com terapias complementares. Assim, o trabalho que realizam vai desde a reorientação alimentar, os chás, o uso de plantas medicinais, a mudança de postura nas relações familiares e cotidianas, até a conexão com o universo e a dimensão da fé e da transcendência. Aliado a isso, constroem-se redes de apoio solidário às pessoas que mais precisam, situação que o grupo de mulheres e outras organizações da comunidade acompanham.

Assim, o vínculo entre o grupo de mulheres, a comunidade e as pessoas que precisam de atenção é um forte aspecto gerador de confiança, companheirismo e responsabilidade para com o outro, o qual, em sua alteridade, se revela como um ser humano capaz e finito.

O processo de acompanhamento, não só com o registro que é feito numa ficha de cada pessoa, mas o engajamento que é possibilitado no grupo do MMC, vai gerando um processo de autoestima, de sentimento de pertença, de construção da libertação e cidadania das mulheres, que deixam de ficar presas às doenças e à condição de vítimas e vão dando um novo sentido às suas vidas. Essa dinâmica educativa $\mathrm{e}$ terapêutica, ao mesmo tempo em que encanta, possibilita a criatividade e o prazer na busca de ser mais gente. Uma das entrevistadas diz: 
As pessoas precisam sentir o que é a vida. Assim como o médico vai ao necrotério, estuda, corta e analisa os cadáveres, para saber como lidar com as doenças, assim também a gente precisa conhecer e saber como funciona a vida, para se acostumar com a dinâmica da vida e das relações. É um novo paradigma e um novo jeito de viver. (L.M.P.D., 2003)

Este modo de cuidar vem ao encontro de responder ao tipo de doenças femininas que são problemas ligados à mulher camponesa e à sua dinâmica de vida e trabalho cotidiano, de modo que, por outro lado, se não forem trabalhados para a mudança dessa realidade, os remédios, por si só, não vão resolver estes problemas de forma estrutural.

Essas práticas mostram que os territórios da vida são mais amplos do que os serviços de saúde e, por isso, apontam a necessidade de pensar a saúde a partir da dinâmica complexa da vida. São práticas centradas na vida e no cuidado com o ser existencial e sujeito que se apresentam e privilegiam o acolhimento, a relaçóes de afeto, respeito às diferenças e de responsabilidade e pertencimento, construtoras de um novo jeito de fazer saúde, de cuidar da vida e do ambiente.

\section{A construção organizativa das mulheres como processo politico-pedagógico}

O caráter pedagógico dos processos organizativos populares não é novidade nem exclusividade da ação das mulheres. Essa dimensão vem sendo construída nas lutas populares no Brasil e na América Latina há muitos anos e tem sua sistematização nas bases assentadas nas práticas e concepções de educação popular. Os processos organizativos emergentes, como é o caso do movimento de mulheres, póem em questão os modelos clássicos de organização social; trazem a visibilidade de setores excluídos; novas formas de se organizar e de exercer o poder; novos conteúdos e metodologias, que desafiam os educadores tanto dos processos formais de educação, quanto das formas específicas de cada organização. Este trabalho do MMC traz como elementos pedagógicos o processo, a participação ativa, a capacidade de ouvir, de fazer, de construção coletiva, de enfrentar os conflitos e contradições.

\section{O caráter educativo da luta das mulheres camponesas}

O processo político de disputa e construção da hegemonia democrática e popular, capaz de consolidar um bloco histórico das classes 
A dimensão educativa da luta por saúde no Movimento de Mulheres Camponesas...

subalternas, a fim de construir uma sociedade nova, baseada em novos valores éticos, políticos, econômicos e sociais, como a justiça, a solidariedade, a participação e o resgate da dignidade humana, constitui-se como um processo político-pedagógico. Fazendo o exercício de identificar elementos pedagógicos da prática dos movimentos sociais populares, especialmente no MMC (RS), cabe ressaltar que estes aspectos se situam nas estratégias políticas desses sujeitos coletivos.

O processo de disputa hegemônica é educativo pela elevação cultural das massas populares. Constitui-se, também, como um processo filosófico, pois as pessoas constroem e reconstroem novas formas de conceber o mundo e de se relacionar com outras pessoas e com a natureza. Nesse sentido, conteúdo e forma se articulam, pois, ao mesmo tempo em que buscam construir uma sociedade nova, o processo em si é construtor do ser humano, de sua dimensão política e de sua autoconstrução.

Quando as mulheres começam a participar de organizações de base, pela sua ação coletiva, vão se dando conta da realidade em que vivem e do contexto histórico que a produziu. Então, sua prática social se converterá em uma prática transformadora, que desafiará novamente as organizações, os dirigentes, os intelectuais orgânicos a formular teoricamente elementos necessários para as exigências postas pela práxis, na correlação de forças da luta hegemônica travada dentro dos espaços da sociedade civil e política. Esse processo de saber interpretar e transformar a realidade de forma consciente e coerente é fonte de poder, sendo a práxis, portanto, a condição indispensável para se construir sujeitos individuais e coletivos, construtores do poder libertador e emancipador das classes populares e das mulheres.

\section{O processo de formação: ênfases político-pedagógicas e dimensões}

$\mathrm{O}$ MMC desenvolve um processo formativo com as mulheres camponesas em duas frentes: na educação formal e na formação específica do Movimento. Nas duas frentes de atuação, a concepção de educação popular é que permeia esses processos. Com relação à formação específica, através da Escola da Mulher, o Movimento desenvolve formação em diferentes níveis, desde atividades de educação de base nos grupos de mulheres e com as comunidades, realizando encontros com cartilhas, materiais informativos, como panfletos, jornais e vídeos, debates 
temáticos, até a realização de cursos de formação para as mulheres coordenadoras dos grupos, militantes e multiplicadoras da promoção da saúde. Também acontecem atividades formativas específicas para dirigentes, educadoras, para casais, crianças e adolescentes. Com relação à formação popular no nível da escolarização, o Movimento atua em parceria com instituiçóes de ensino, desenvolvendo processos de alfabetização, cursos de $1^{\circ}$ e $2^{\circ}$ graus para as mulheres e convênios com universidades públicas para cursos de graduação e pós-graduação.

\section{Desafios político-pedagógicos à educação popular em saúde que emergem desta experiência}

A experiência desenvolvida pelo MMC (RS) está inserida num contexto de práticas que se poderia chamar de "redes sociais de saúde popular", que realizam açôes de promoção da saúde e prevenção de doenças, utilizando a diversidade de terapias naturais, tradicionais, populares e integrativas para cuidar da saúde e da vida. São práticas de resistência e afirmação de um novo jeito de pensar e produzir saúde. Estas práticas ${ }^{2}$ apontam desafios. Entre eles, um desafio fundamental é a necessidade de construção de um sistema público de saúde mais democrático, que seja capaz de ouvir a população, que cuide das pessoas como sujeitos, que enfrente as causas das doenças e que articule atores e possibilite a intersetorialidade.

Outro desafio é a exigência ética de reconhecimento e fortalecimento das práticas populares tradicionais e integrativas de saúde, como formas de atenção à saúde que precisam de reconhecimento nas políticas públicas para repensar as políticas de saúde, para que não se apresentem como práticas marginais, mas legítimas. O reconhecimento, a autonomia e a potencialização são necessários para que se tornem cada vez mais reflexivas, a partir dos instrumentos da educação popular, e sejam qualificadas como processos construtores de vida, saúde e cidadania das mulheres e de grupos excluídos da sociedade.

Além disso, essas práticas colocam como desafio a articulação entre os sujeitos (movimentos, grupos e entidades) dessas experiências populares, a fim de realizar processos formativos comuns a partir da concepção de educação popular; bem como a construção de articulações mais amplas com os sujeitos das práticas populares de saúde, no 
A dimensão educativa da luta por saúde no Movimento de Mulheres Camponesas...

sentido de realizar ações e lutas coletivas capazes de alterar a correlação de forças no "jogo de interesses", naquilo que produz doença e ameaça a dignidade e a vida.

Exigências e desafios aos educadores(as) populares em saúde

A investigação realizada possibilitou identificar um conjunto de exigências que se colocam a educadores(as) para enfrentar os desafios que a complexidade da dinâmica educativa popular apresenta. Assim, colocam-se como exigências de natureza política a clareza do projeto popular de sociedade, do projeto do Movimento, e o compromisso com a construção dos mesmos. Além disso, é fundamental que os(as) educadores(as) assumam o compromisso com a educação como mediação do caminho de libertação e humanização, o que requer o domínio da concepção metodológica da educação popular.

A par disso, é requerido dos(as) educadores(as) o domínio dos conteúdos gerais, da análise da realidade e da construção do conhecimento das mulheres, de gênero, classe, agricultura ecológica e, especialmente, da área da saúde, de concepções e práticas, dos processos de saúde-doença, das linhas e modos de cuidado, de políticas de saúde, entre outros.

Aquele que se propõe a ser educador(a) popular em saúde precisa desenvolver habilidades de pensar e repensar processos a partir da realidade concreta; de análises e sínteses a partir do grupo; de estabelecer relações; de diferenciar o principal do secundário; de globalizar e de construir coletivamente estratégias e propostas que impulsionem a ação popular das mulheres; capacidade de formulação e implantação de estratégias de ação popular e habilidades para trabalhar com grupos; saber manejar a tensão entre a palavra e o silêncio; diferenciar a realidade do educador e do educando; vincular teoria e prática = práxis; evitar o espontaneísmo sem cair na manipulação. É fundamental o desafio de construir uma postura de sujeito comprometido, democrático, aberto ao novo; de respeito às diferenças e ao coletivo, com linguagem simples e adequada aos níveis de cada grupo.

Para melhor compreender essa dinâmica, desafios e exigências, Paulo Freire, ${ }^{3}$ educador popular brasileiro inserido no processo educativo e organizativo das classes populares, nos revela que a base 
fundamental nas relaçóes é o diálogo, pois é o sentimento do amor tornado ação.

Ao refletir acerca do caráter pedagógico da luta por saúde no MMC, foi possível identificar que suas práticas concretas traduzem uma leitura de realidade segundo a qual as grandes questôes que sangram nossa nação se articulam na reflexão sobre os processos de viver, de ter saúde ou de adoecer. Além disso, tal reflexão mostra que os processos políticos educativos têm uma utopia de construção de uma nova sociedade, com novas relaçôes humanas e com a biodiversidade como pano de fundo. Revela a importância da organização autônoma das várias esferas organizativas das classes populares e de suas dimensões étnico-raciais, de gênero, de orientação sexual, religiosa e geracional. As práticas de saúde do MMC traduzem uma visão popular de educação, ou seja, uma educação não aprisionada na escola, embora reconheça sua importância estratégica para nos tornarmos humanos no tempo histórico, ainda que tenhamos vocação ontológica para ser mais. Além disso, estas experiências revelam que as atividades educativas ocorrem em todos os espaços e, quanto mais organizado o movimento social, mais intencionalidade educativa se apresenta.

Além desses aspectos, há uma compreensão mais profunda da educação popular como concepção de educação libertadora, e não de uma educação para o povo; uma educação calcada no compromisso com a transformação da sociedade e com a construção de sujeitos individuais e coletivos e centrada na reflexividade, a fim de conscientizar, não de iludir ou convencer. Nesse sentido, outro grande desafio que se coloca é a abertura para captar o novo que emerge das práticas, sem ter a pretensão de determiná-las ou legitimá-las, mas, sim, de problematizá-las. Essas práticas reforçam a conviçção de que colocar o povo no centro do processo ainda é o melhor caminho - historicamente comprovado -, e a síntese desse novo momento histórico parece estar apenas começando!

Esse desafio se coloca a todos os que estão comprometidos com a construção de uma sociedade verdadeiramente justa e solidária, na perspectiva socialista, e a todos os que experimentam e admiram a realização de algo quase invisível: o valor da vida, da dignidade da pessoa, da função criadora do trabalho, da solidariedade, da liberdade e da sabedoria, que integra o pensar, o sentir e o agir numa unidade dialética. 
A dimensão educativa da luta por saúde no Movimento de Mulheres Camponesas...

Finalmente, coloca-se o desafio de repensar a práxis numa dimensão humanista e pedagógica, resgatando a utopia e a esperança de uma nova sociedade, na qual os direitos sociais sejam garantias de direitos individuais, em que a liberdade seja a expressão da garantia dos direitos de vida e cidadania; uma sociedade onde as relaçôes entre homens e mulheres sejam construídas a partir de um novo modo de viver em família e em comunidade; um modo de vida pautado pelo diálogo, pela solidariedade, respeito, amor, carinho, confiança, e no qual o exercício responsável da liberdade seja a expressão viva e cotidiana de todos os cidadãos.

\section{Recebido em abril de 2008 e aprovado em maio de 2009.}

\section{Notas}

1. Está organizado em mais de quinhentos grupos de base, em 14 regiōes, envolvendo aproximadamente cem municípios do RS e organizado nacionalmente em 19 estados. Faz parte da Via Campesina e estabelece relações com organizaçôes do campo em nível latino-americano, como a CLOC e Via Campesina Mundial, bem como com outros movimentos de mulheres e com a Marcha Mundial de Mulheres, e parcerias com entidades de cooperação em nível nacional e internacional.

2. As práticas populares de saúde do MMC (RS) e também de movimentos sociais populares que se articulam na ANEPS (Articulação Nacional de Movimentos e Práticas de Educação Popular e Saúde) vêm dando sinais de desafios como os que estão sendo apontados aqui.

3. Paulo Freire foi um educador popular brasileiro que iniciou seu trabalho educativo no Movimento de Cultura Popular no Nordeste, em torno de 1961. Ele construiu uma proposta pedagógica, um método, ou um processo pedagógico pelo qual a educação servisse para libertar as pessoas e não para ensiná-las e torná-las domesticadas. Escreveu vários livros, entre eles: Pedagogia do oprimido, Educação como prática de liberdade, Educação e mudança, Cartas à Guiné-Bissau, Pedagogia da esperança, Pedagogia da autonomia.

\section{Referências}

DARON, V.L.P. Educação, cultura popular e saúde: experiências de mulheres trabalhadoras rurais. 2003. Dissertação (Mestrado em Educação) - Faculdade de Educação, Universidade de Passo Fundo, Passo Fundo.

FREIRE, P. Pedagogia do oprimido. 15. ed. Rio de Janeiro: Paz \& Terra, 1985. 
FREIRE, P. Reflexão critica sobre as virtudes da educadora ou do educador. São José: IIDH; Anistia Internacional, 1995.

FREIRE, P. Pedagogia da autonomia: saberes necessários à prática educativa. São Paulo: Paz \& Terra, 1996.

GEBARA, I. Rompendo o silêncio: uma fenomenologia feminista do mal. Petrópolis: Vozes, 2000.

GRAMSCI, A. Os intelectuais e a organização da cultura. Trad. Carlos Coutinho. 4. ed. Rio de Janeiro: Civilização Brasileira, 1982.

MARCON, T. Cultura popular e desafios pedagógicos. In: RaYs, O.A. (Org.). Trabalho pedagógico: realidades e perspectivas. Porto Alegre: Sulina, 1999. p. 255-266.

MINAYO, M.C.S. O desafio do conhecimento: pesquisa qualitativa em saúde. 4. ed. São Paulo: HUCiTEC-ABRASCO, 1996.

MURARO, R.M. Sexualidade da mulher brasileira: corpo classe social no Brasil. 4. ed. Petrópolis: Vozes, 1983.

PALUDO, C. Educação popular em busca de alternativas: uma leitura desde o campo democrático e popular. Porto Alegre: Tomo, 2001. 